\title{
VEINTICINCO AÑOS DE CUESTIÓN RELIGIOSA Y SU SOLUCIÓN CONSTITUCIONAL
}

\author{
JOSÉ ANTONIO SOUTO PAZ \\ Catedrático de Derecho Eclesiástico del Estado \\ Universidad Complutense de Madrid
}




\section{SUMARIO}

1. LAS "CUESTIONES HEREDADAS" Y EL DEBATE CONSTITUCIONAL. 2. LA DIGNIDAD DE LA PERSONA HUMANAY LA LIBERTAD DE COSMOVISIÓN. 3. ¿UN ESTADO LAICO? 4. UN EJERCICIO DE SOCIOLOGÍA RELIGIOSA: LA COOPERACIÓN DE LOS PODERES PÚBLICOS CON LAS CREENCIAS RELIGIOSAS CON ARRAIGO SOCIAL. 5. LA PROYECCIÓN NORMATIVA DEL TEXTO CONSTITUCIONAL: LA EXPERIENCIA DE VEINTICINCO AÑOS. 


\title{
VEINTICINCO AÑOS DE CUESTIÓN RELIGIOSA Y SU SOLUCIÓN CONSTITUCIONAL
}

POR

\author{
JOSÉ ANTONIO SOUTO PAZ
}

Catedrático de Derecho Eclesiástico del Estado

Universidad Complutense de Madrid

\section{LAS “CUESTIONES HEREDADAS"Y EL DEBATE CONSTITUCIONAL}

Entre las variadas cuestiones que se plantean necesariamente a la hora de abordar la elaboración de un texto constitucional, algunas presentan, como rasgo propio y peculiar, su dificultad para hallar una solución adecuada a lo largo de un dilatado proceso histórico. Entre otras cuestiones heredadas destacaban, en el último proceso constituyente, la cuestión de la forma de gobierno (monarquía/república), la organización del Estado (Estado unitario/Estado descentralizado) y la cuestión religiosa (confesionalidad estatal/separación). Prescindiendo de las dos primeras cuestiones, que no están previstas en esta reflexión, es oportuno recordar, sin embargo, que las tres aparecen unidas por un lema histórico: Dios, Patria, Rey.

La Monarquía como vértice del Estado unitario y centralizado, que pretendió el absolutismo político, ha ido acompañado del adjetivo católico, monarquía católica, desde la aparición en España de lo que se ha dado en llamar el Estado moderno. No puede extrañar, por tanto, que, a la hora de proceder a la sustitución del Antiguo Régimen, 
hayan sido cuestiones debatidas a lo largo de más de un siglo y se hayan convertido en cuestiones litigiosas con el advenimiento de la Segunda República. Su trágico final y la implantación de un régimen inspirado en el antiguo régimen han convertido estas cuestiones en asuntos pendientes y heredados, que el constituyente no podía olvidar, más bien, al contrario, necesitaba abordar y procurar resolver satisfactoriamente.

La cuestión religiosa, aunque alcanzó su momento culminante en la Segunda República, tiene ya una dilatada historia, cuyos origenes habría que situarlos en la Constitución de 1812. El siglo XIX ha sido un espectador sensible de las tendencias liberales, defensoras de la libertad religiosa, y las posturas reaccionarias o conservadoras, manifiestamente opuestas al reconocimiento de este derecho, oscilando ente la intolerancia religiosa y la mera tolerancia. La solución constitucional de 1978, como veremos a continuación, supera esta cuestión con brillantez, al situar la "cuestión religiosa" en el ámbito de los derechos fundamentales y de las libertades públicas, adoptando así una postura personalista, en la que se garantiza la libertad individual y colectiva en el ámbito ideológico y religioso. La superación de la vía institucionalista, de larga tradición histórica en nuestro país, parecia lograda a la vista de los dos primeros apartados del artículo 16 de la Constitución. La igualdad de todas las confesiones se ratifica, igualmente, con el principio de que ninguna confesión tendrá carácter estatal. El problema, sin embargo, surge con la inclusión en el último apartado de un mandato a los poderes públicos para que mantengan relaciones de cooperación con la Iglesia católica y las demás confesiones. Pero, ¿qué significa mantener relaciones de cooperación? Aquí comienzan los problemas.

\section{LA DIGNIDAD DE LA PERSONA HUMANA Y LA LIBERTAD DE COSMOVISIÓN}

La historia constitucional española mantiene como una constante permanente la adopción de una postura determinada del Estado ante la religión. Tal vez, con mayor precisión, habría que matizar esta referencia diciendo que esa actitud se refiere a su relación con las confesiones religiosas, es decir, a la relación institucional del Estado ante una o varias confesiones religiosas. Desde la "profética" declaración de la Constitución de 1812, que manifiesta que «la religión de la Nación española es y será perpetuamente la católica, apostólica, romana, única verdaderan (art. 12) hasta la concluyente declaración de la Consti- 
tución de 1931: "El Estado español no tiene religión oficial», esta actitud de los sucesivos constituyentes ha sido constante.

Este carácter institucional ha tenido el efecto inmediato de subordinar la libertad de los ciudadanos a la actitud institucional del Estado. La posición del Estado en la Constitución de 1812 condujo a una actitud de total intolerancia respecto a las demás confesiones y, en consecuencia, a la negación absoluta de la libertad religiosa de los ciudadanos. La desvinculación del Estado de cualquier confesión religiosa, en la Constitución de 1931, permitió el reconocimiento de la libertad religiosa, pero condicionada a la actitud laicista del Estado, que queda reflejada en las prohibiciones y limitaciones establecidas en los artículos 26 y 27 respecto al ejercicio colectivo de la libertad religiosa.

Una actitud semejante, aunque desde perspectivas manifiestamente distintas, se aprecia en el régimen franquista, que declara solemnemente la confesionalidad del Estado y concede a los ciudadanos una cierta tolerancia religiosa. Cuando el Concilio Vaticano II reconoce, en 1965, el derecho al ejercicio civil de la libertad religiosa, el régimen franquista se ve obligado, en virtud de la confesionalidad del Estado, a modificar sus leyes fundamentales y reconocer el derecho de libertad religiosa a los ciudadanos, pero siembre subordinado al principio de confesionalidad católica estatal, lo que da lugar a la coexistencia de dos regímenes de libertad religiosa: la de los católicos y la de los no católicos, como se desprende de la Ley de libertad religiosa de 1967.

Este planteamiento institucionalista ha sido superado, en principio, por la Constitución española actualmente vigente, que no realiza ninguna declaración respecto la identidad del Estado en materia religiosa. Por el contrario, dentro del capítulo dedicado a los derechos y libertades y, en concreto, en la sección $1{ }^{a}$, dedicada a los derechos fundamentales y las libertades públicas, el artículo 16 dispone que: "Se garantiza la libertad ideológica, religiosa y de culto de los individuos y de las comunidades sin más limitación, en sus manifestaciones, que la necesaria para el mantenimiento del orden público protegido por la ley".

Coherente con lo dispuesto en el artículo 10.1 de la CE, en el que se establece como fundamento del orden político y de la paz social "la dignidad de la persona, los derechos inviolables que le son inherentes, el libre desarrollo de la personalidad...", el artículo 16 garantiza ese ámbito de libertad personal en virtud del cual cada persona puede conformar su propia concepción de la vida y del mundo, es decir, su propia cosmovisión. Por eso se condensa, en un mismo precepto consti- 
tucional, la libertad ideológica y la libertad religiosa, es decir, el reconocimiento de que la persona humana es libre de elaborar su propia concepción de la vida de acuerdo con sus propias ideas, mediante la asunción de una determinada ideología o por la adhesión a unas concretas creencias religiosas. Lo sustantivo es la libertad, lo adjetivo es el origen y el contenido de esa concepción. La variedad de opciones es tan amplia que los textos internacionales utilizan diversos términos: libertad de pensamiento, de conciencia, de creencias, de convicciones, etc. Esta variedad de términos no altera el significado y contenido fundamental de lo que es el elemento sustantivo: la libertad de cosmovisión.

Precisamente, para evitar interpretaciones equivocas, el Comité de Derechos Humanos de las Naciones Unidas, en un Comentario al artículo 18 del Pacto Internacional de Derechos Civiles y Políticos de 20 de junio de 1993, expone los siguientes criterios hermenéuticos:

a) El derecho a la libertad de pensamiento, conciencia y religión, que incluye la libertad de creencias, descrito en el artículo 18 PIDC, es amplio y denso. Abarca la libertad de pensamiento sobre cualquier tema, las convicciones personales y la adhesión a una religión o a unas creencias, ya sea manifestado de una forma individual o colectiva.

b). La libertad de pensamiento y de conciencia se protegen en la misma medida que la libertad de religión y de creencias.

c) El carácter fundamental de estas libertades se refleja en que no pueden ser derogadas ni siquiera en situaciones de emergencia.

d) Las creencias deístas, no deístas y ateas, así como el derecho a no profesar ninguna religión o creencia están protegidas por el artículo 18.

e) Los términos creencia y religión han de ser interpretados ampliamente. No puede limitarse el artículo 18 a las religiones tradicionales con características institucionales o prácticas análogas a las de las religiones tradicionales.

En virtud de los dispuesto en el artículo 10. 2., este Comentario del Comité de Derechos Humanos de Naciones Unidas deberá ser tenido en cuenta necesariamente a la hora de interpretar el artículo 16 de la Constitución. Dicho Comentario viene a ratificar cuanto hemos dicho anteriormente $y$, tal vez, frente a otras apreciaciones doctrinales, opinamos que no se puede considerar este precepto constitucional como 
el precepto de la religión, sino como un precepto dedicado a una libertad individual y colectiva, una libertad específicamente humana, al ser el hombre el único ser vivo capaz de ser consciente de su propio mundo (J. MARÍAS). Es evidente que una gran parte de la humanidad conforma su propia cosmovisión de acuerdo con unas creencias religiosas; pero esa otra parte que no adopta ese criterio y elabora su propia concepción de la vida o la ajusta a una determinada concepción ideológica o a un sistema filosófico o ético, todos esas personas gozan de la misma libertad, la libertad de autodeterminación en la elección de su propia concepción del mundo y de la vida, es decir, de su propia cosmovisión.

La gran novedad de la Constitución vigente, respecto a los textos constitucionales precedentes, reside en que esta libertad nace de la propia dignidad humana, le corresponde a todos por igual y es inviolable e inalienable y no depende de la autocalificación del Estado en relación con la religión. Se trata, obviamente, de una concepción personalista frente a las precedentes concepciones institucionalistas $y$ cualquier otro añadido que pretenda menoscabar esta dimensión personalista, en aras de un mayor protagonismo institucional, resulta extemporáneo $e$, incluso, si su alcance vulnera los derechos fundamentales garantizados por la Constitución, podría devenir inconstitucional.

\section{3. ¿UN ESTADO LAICO?}

Con frecuencia, podemos leer o escuchar en los medios de comunicación declaraciones y opiniones que manifiestan de manera categórica que el Estado español es un Estado laico y para corroborar esta declaración se suele añadir: «lo dice la Constitución». Ciertamente, esta expresión carece de fundamento, puesto que la Constitución no menciona en ningún precepto que el Estado español sea laico. Es más, el único Estado de la Unión Europea, en el que su Constitución hace referencia a esta característica del Estado es la francesa de 1958, actualmente vigente, que califica a la República como laica (artículo 1).

La Constitución española vigente elude, como hemos dicho antes, cualquier referencia a la identidad del Estado en relación con la religión. Para dejar constancia de este hecho ni siquiera utiliza la habitual calificación de que el Estado es aconfesional. En un texto, como el artículo 16, dedicado a la libertad ideológica y religiosa, individual y colectiva, la declaración constitucional toma como punto de partida 
a las confesiones y no al Estado para decir que «ninguna confesión tendrá carácter estatal». El pronunciamiento se refiere a las confesiones y no al Estado. Aunque puede parecer que ambos supuestos son equivalentes, es oportuno advertir que el constituyente ha querido dejar claro que el Estado no tiene que hacer ninguna declaración sobre esta cuestión y que se declara incompetente para definirse en relación con las creencias religiosas, ateisticas o agnósticas, filosóficas o ideológicas.

El mundo de las creencias, de las convicciones, de las ideologías pertenece a la sociedad, no al Estado. Los poderes públicos deben garantizar la libertad y el pluralismo de la sociedad y en la sociedad, para que los individuos y comunidades puedan ejercer libremente su libertad de cosmovisión, en público y en privado. El Estado no tiene nada que decir al respecto, porque no es competente para valorar las diferentes opciones ideológicas o religiosas y, por supuesto, es incompetente para elegir como propio un partido político, un sindicato o una confesión religiosa.

Como consecuencia natural de esta incompetencia del Estado se produce la separación entre el Estado y las confesiones religiosas. Una separación que, rectamente entendida, supone que la independencia y autonomía del Estado y la autonomía de cada confesión religiosa excluyen cualquier interferencia de las funciones estatales en el ámbito interno de las confesiones religiosas y, recíprocamente, de las funciones eclesiásticas en el ámbito interno del Estado. En el ámbito doctrinal supone, igualmente, que el Estado es neutral ante las propuestas o creencias de cada confesión y, como lógica consecuencia, el Estado no puede asumir como propias o adherirse a la doctrina de ninguna de las confesiones.

Separación y neutralidad son, por consiguiente, los dos pilares en los que se asienta la autonomía del Estado y la autonomía de las confesiones en un sistema constitucional de libertades. Se podría alegar que esas dos notas son, precisamente, las que identifican al Estado laico en contraposición al Estado confesional; sin embargo, habría que decir que tales afirmaciones son parcialmente ciertas, pero, en todo caso, incompletas. El Estado laico no deja la cuestión religiosa al libre juego y desarrollo de la sociedad; muy, al contrario, adopta una postura negativa $o$, al menos, limitadora de la libertad religiosa. Es decir, el Estado toma postura frente al hecho religioso y, por consiguiente, adopta una postura institucional frente a las confesiones, siguiendo, en este caso, el modelo confesional, pero "a sensu contrarion. 
Algunas manifestaciones, deducidas de la legislación, la doctrina y la praxis de la República francesa, el Estado laico por excelencia, pueden ilustrar las anteriores afirmaciones. Las leyes de 1905 y 1907 limitan el derecho de libertad de asociación religiosa en relación con el régimen jurídico de las demás asociaciones. Esta legislación influyó decisivamente en la Constitución española de 1931, cuyo artículo 26 es una manifestación clara de la subordinación del derecho de libertad religiosa al laicismo estatal. La prohibición de destinar fondos públicos a la asociaciones religiosas, aunque sea para el cumplimiento de fines de interés social, revela una actitud manifiestamente discriminatoria de las asociaciones religiosas en relación con las demás asociaciones, que ha debido ser corregido, sucesivamente y entre notables debates, por la jurisprudencia. La prohibición del uso de símbolos religiosos en centros públicos que, todavía, ha dado lugar, recientemente, a la suspensión de empleo de una funcionaria francesa por el uso del velo en su lugar de trabajo "en aras del Estado laico", refleja que la libertad individual y colectiva se limita y subordina a un prejuicio del Estado laico que, en estos casos, es simplemente un Estado antirreligioso o arreligioso, lo cual se compadece mal con el derecho de libertad religiosa individual y colectiva, garantizado constitucionalmente y renuncia a una cierta identidad del Estado ante la religión.

Pero, quizás, el carácter emblemático del Estado laico se centre en el ámbito escolar. La solución que propone el laicismo francés es muy simple: para preservar el pluralismo religioso es necesario suprimirlo de la escuela pública. "Está prohibido llevar una insignia en un establecimiento determinado en la medida en que esto constituye una manifestación en sentido contrario. El respeto por todas las creencias obliga, no a enturbiar la nuestra, sino a manifestarla con cierta reserva...La enseñanza pública francesa se esfuerza en ser neutral, y no se erige en propagandista ni en apologista de ninguna fe, ni en censura ni retractora de ninguna filosofía. La instrucción que se da es arreligiosa, no antirreligiosa" (Guy DEBIERE).

La postura más benigna del laicismo propone ocultar la religión, olvidando que es una realidad social y cultural presente en la sociedad. Es evidente que la escuela pública no debe adoctrinar ni en el plano religioso ni tampoco en el filosófico o ideológico. Pero, ¿eso supone que no se puede enseñar filosofía, historia de las ideas políticas o historia y cultura religiosa? El laicismo beligerante llega mucho más lejos: "La neutralidad es y fue una gran mentira:Tal vez fue necesaria cuando se forjaba la ley escolar, en medio de las impetuosas cóleras de la derecha. Se presentó esta quimera de la neutralidad para tran- 
quilizar a algunos tímidos cuya coalición hubiera sido un obstáculo al principio de la ley... (pero) nunca hemos tenido otro designio que hacer una Universidad antirreligiosa, y antirreligiosa de una manera activa, beligerante y belicosa" (diputado VIVIANI).

El Estado laico parte de una concepción negativa de la presencia de la religión en el ámbito público. Esto es incompatible con el reconocimiento del derecho de libertad ideológica y religiosa y del consiguiente pluralismo social. Un Estado de libertades no puede ocultar, excluir o expulsar aquellos aspectos sociales legítimos, cuyo ejercicio está protegido y garantizado por la propia Constitución. Cosa muy distinta es que se manifieste a favor o en contra de una determinada ideología o pretenda adoctrinar a los estudiantes o a los ciudadanos en un determinado sentido. El ámbito de protección y garantía de las libertades por parte del Estado acaba cuando su actuación puede poner en riesgo o vulnerar esas mismas libertades.

La Constitución española vigente, a diferencia de la de 1931, muy influenciada por el laicismo francés, no ampara ni protege ninguna de las manifestaciones que se consideran identificadoras del Estado laico: limitación de los derechos de las asociaciones religiosas; prohibición de destinar fondos públicos a estas asociaciones, aunque sea para el cumplimiento de fines sociales; exclusión de los signos religiosos de los establecimientos públicos, aunque sean parte de la vestimenta de un ciudadano en el ejercicio de su libertad religiosa; exclusión de la religión de la escuela pública, etc. La razón es muy sencilla. La Constitución respeta y protege las libertades de los ciudadanos en el ámbito ideológico y religioso y se considera incompetente para pronunciarse sobre esas opciones, salvo que, en su ejercicio, se vulneren los derechos fundamentales y las libertades públicas o el orden público protegido por la ley. El Estado español, por consiguiente, no es un Estado confesional ni, tampoco, un Estado laico, porque renuncia a tener una identidad religiosa o arreligiosa, considerando que se trata de una materia que corresponde a la sociedad y, sobre la cual, el Estado se declara incompetente.

4. UN EJERCICIO DE SOCIOLOGÍA RELIGIOSA: LA COOPERACIÓN DE LOS PODERES PÚBLICOS CON LAS CREENCIAS RELIGIOSAS CON ARRAIGO SOCIAL

La principal función del Estado, en relación con la libertad ideológica y religiosa, consiste en garantizar su libre ejercicio por parte de 
las personas, individual o colectivamente. Ello no impide que, sin vulnerar la libertad de los individuos y de las comunidades, pueda colaborar en la promoción de actividades conducentes al ejercicio de este derecho o a la realización de actividades de interés social promovidas por los ciudadanos o los grupos de naturaleza ideológica o religiosa.

Esta cooperación, que sería incompatible con la identidad propia de un Estado laico, aparece expresamente reconocida en el texto constitucional, estableciendo un mandato a los poderes públicos para que mantengan relaciones de cooperación con las confesiones religiosas. El texto puede resultar sorprendente si se tiene en cuenta que la disposición del Estado Social, para atender y satisfacer la "procura existencial" (FORSTHOFF), mediante las prestaciones adecuadas, se convierte en mandato imperativo en aquellos sectores (derechos sociales, económicos y culturales), que expresamente menciona la Constitución (artículos 39-52); pero, no ocurre lo mismo en el ámbito de las libertades públicas, donde el deber de los poderes públicos es garantizar el derecho-libertad, pero no satisfacer un derecho-prestación.

El deber de mantener relaciones de cooperación con las confesiones religiosas constituye, así, una excepción en el ámbito propio de las libertades públicas. La sorpresa que puede producir este mandato constitucional se incrementa cuando el texto constitucional dispone que los poderes públicos «tendrán en cuenta las creencias religiosas de la sociedad española". Da la impresión de que los poderes públicos deberían crear, a tenor de lo dispuesto en dicho precepto constitucional, un observatorio religioso, que permitiera cuantificar las creencias y los creyentes existentes en nuestra sociedad. Tarea un tanto compleja que tropieza, antes de nada, con lo dispuesto en el apartado anterior del mismo artículo 16, que garantiza que «nadie podrá ser obligado a declarar sobre su ideología, religión o creencias". La primera fuente de información, que sería la facilitada por los propios ciudadanos, resulta inviable por la inmunidad de coacción garantizada por la propia Constitución. Habría que estar, por tanto, a lo manifestado por las propias confesiones, que no podría ser contrastado, en virtud de la especial protección de datos personales que la legislación otorga a los datos sensibles protegidos por el artículo 16 de la Constitución. Las dificultades para dar cumplimiento a este mandato se han podido comprobar en la práctica al tratar de concretar y aplicar el concepto de arraigo, requisito necesario para que las confesiones religiosas puedan suscribir Acuerdos con el Estado español.

La segunda cuestión que la simple lectura de la Constitución pudiera plantear es la interpretación del significado de la expresión 
relaciones de cooperación. ¿Qué? ¿Cuáles? ¿Cómo? Los posibles interrogantes se desvanecieron pronto, puesto que, cinco días después de la promulgación de la Constitución, el tres de enero de 1979, el Gobierno español suscribía cuatro Acuerdos con la Santa Sede, utilizando para ello el procedimiento previsto para los Tratados internacionales (artículos 93-96 CE). Este hecho permitió interpretar qué quería decir la Constitución al referirse a las relaciones de cooperación y, además, la razón por la que fue enmendado el Anteproyecto de Constitución, incluyendo la expresión "Iglesia Católica y demás confesiones", en sustitución de la más lacónica "confesiones religiosas" que aparecía en el Anteproyecto.

La incorporación de este apartado encaminado a establecer un mandato a los poderes públicos para que, teniendo en cuenta las creencias religiosas de la sociedad española, mantengan relaciones de cooperación con la Iglesia Católica y las demás confesiones, tiene una finalidad explícita: otorgar cobertura constitucional a los Acuerdos que se habian venido gestando, desde el mes de julio de 1976 hasta la conclusión de la Constitución, entre el Gobierno español y la Santa Sede. La pretensión, explicitada ya en el Acuerdo del 26 de julio de 1976, de proceder a la sustitución del Concordato de 1953 por una serie de Acuerdos parciales, pero con el mismo rango de tratado internacional, encontraba, en el artículo 16 de la Constitución, la cobertura y la protección para sobrevivir a los azares de la vida política y a la alternancia del poder. Por otra parte, el texto así interpretado permite reconducir la dimensión personalista del artículo 16, como garantía de las libertades individuales y colectivas, para recuperar la dimensión institucionalista de tan vieja tradición en las relaciones Iglesia y Estado.

¿Existia alguna razón que justificase la necesidad de suscribir un nuevo Concordato? Conviene recordar que el Concordato ha sido un instrumento jurídico, con una notable tradición en la Iglesia Católica, utilizado para crear, mediante un tratado bilateral, un régimen jurídico privilegiado para la Iglesia, a cambio de una serie de concesiones o privilegios eclesiásticos a favor del monarca o, más tarde, del Estado. Este sistema entró en crisis, en el propio ámbito eclesiástico, a partir del Concilio Vaticano II, en el que se proclama que la Iglesia no pone "su esperanza en privilegios dados por el poder civil; más aún renunciará al ejercicio de ciertos derechos legítimamente adquiridos tan pronto como conste que su uso puede empañar la pureza de su testimonio o las nuevas condiciones de vida exijan otra disposición» (Const. Gaudium et Spes, n. 76). 
Esta nueva actitud hizo entrar en crisis el modelo concordatario, considerado como expresión de un régimen de privilegios que la doctrina conciliar rechazaba de plano. Sin embargo, después de un inicial cuestionamiento doctrinal del sistema, la praxis eclesiástica, poco tiempo después, limitó dicho rechazo a una cuestión meramente terminológica, al sustituir la denominación concordato por la de acuerdo o acuerdos sectoriales. En esta fase de evolución de la doctrina y praxis eclesiástica hay que situar la firma de los Acuerdos entre el Estado español y la Iglesia Católica. ¿Era necesario crear un régimen jurídico específico para la Iglesia Católica en un Estado que garantiza las libertades individuales y colectivas?

Desde el punto de vista eclesiástico, la exigencia de la Iglesia de que pueda uen todo momento y en todas partes predicar la fe con auténtica libertad, enseñar su doctrina sobre la sociedad, ejercer su misión sobre los hombres sin traba alguna y dar su juicio moral, incluso sobre materias referentes al orden político, cuando lo exijan los derechos fundamentales de la persona...) (Const. Lumen Gentium, n. 76), parece que está plenamente garantizada por el ordenamiento jurídico español, resultando innecesario, desde ese punto de vista, crear un régimen jurídico especial al margen del régimen general. Desde el punto de vista del Estado, parece injustificado crear un régimen especial para el ejercicio de las libertades públicas o para la concesión de determinadas prestaciones que puedan vulnerar el principio de igualdad, cuando la diferencia de trato en relación con otras confesiones religiosas va más allá de lo cuantitativo para generar diferencias cualitativas (L. MARTÍN-RETORTILLO).

\section{LA PROYECCIÓN NORMATIVA DELTEXTO CONSTITUCIONAL: LA EXPERIENCIA DE VEINTICINCO AÑOS}

El desarrollo normativo de la Constitución, a través de la legislación o de los tratados internacionales, ha incrementado las diferencias de régimen jurídico entre las diferentes confesiones religiosas. Constituye ya un tópico hablar de dos regímenes jurídicos claramente distintos. Por una parte, el régimen jurídico nacido de los Acuerdos con la Iglesia Católica y, por otra parte, el régimen jurídico de las demás confesiones religiosas, establecido por la Ley Orgánica de Libertad religiosa. Este segundo régimen se desdobla en dos: el derivado de los Acuerdos suscritos por el Estado con la Federación de Entidades Religiosas Evangélicas, con las Comunidades Israelitas y con la Comisión Islámica y el aplicable a las Confesiones simplemente ins- 
critas, que se regirán únicamente por la Ley Orgánica de Libertad Religiosa.

La Ley de Libertad Religiosa, que pretende desarrollar el artículo 16 de la Constitución, estableciendo un régimen común y general para los individuos y las comunidades, se convierte así en un régimen subsidiario. La Ley no es aplicable a la Iglesia Católica que, al suscribir un Tratado internacional se rige por el mismo, de tal manera que la legislación general solo es aplicable a las demás confesiones, tal y como ocurría en el régimen franquista, en el que la Ley de Libertad Religiosa de 1967 se aplicaba a las confesiones católicas, mientras que la Iglesia Católica se regía por el Concordato de 1953.

La existencia de tres regímenes jurídicos distintos da lugar a diferencias de trato manifiestas, no solo entre las distintas confesiones religiosas sino, también, entre los ciudadanos por razón de sus creencias religiosas. La eficacia civil del matrimonio religioso, la enseñanza religiosa en los centros docentes, la asistencia religiosa en establecimientos públicos (Fuerzas Armadas, establecimientos penitenciarios, Centros hospitalarios, etc.) es cualitativamente distinta para los ciudadanos de acuerdo con sus creencias religiosas.

La praxis politica y administrativa ha agravado esta situación. Renunciando a exponer todos los supuestos de excepción al régimen común que se derivan del actual sistema normativo, vamos a comentar tan solo algunos casos significativos

a) La financiación estatal de la Iglesia Católica, prevista en los correspondientes Acuerdos, parte del principio de que «el Estado no puede ni desconocer ni prolongar indefinidamente obligaciones juridicas contraídas en el pasado", al tiempo que "la Iglesia Católica declara su propósito de lograr por sí misma los recursos suficientes para la atención de sus necesidades». El sistema de financiación estatal acordado con la Iglesia Católica es cualitativamente distinto al de las demás confesiones, por lo que el propio régimen acordado es transitorio, pasando del sistema de dotación presupuestaria global al de asignación tributaria, de acuerdo con los plazos previstos en el propio Acuerdo. Veinticuatro años después de la firma del Acuerdo no se ha cumplido de hecho ninguna de las previsiones acordadas. Aunque con notable retraso sobre los plazos estipulados, se pasó del sistema de dotación presupuestaria global al sistema de asignación tributaria; de hecho, sin embargo, se han mantenido las cantidades establecidas en el sistema previo, dado que el nuevo sistema de asignación tributaria resulta, año tras año, inferior a dichas cantidades, por lo que se procede anualmente a la condonación de la deuda por parte de las Cor- 
tes Generales. El régimen privilegiado de la Iglesia Católica en este apartado resulta difícilmente justificable.

b) La confusión entre funciones estatales y funciones eclesiásticas se hace evidente, entre otros casos, en el régimen del profesorado de religión católica. El correspondiente Acuerdo dispone que la situación económica de los profesores de religión católica "se concertará entre la Administración Central y la Conferencia episcopal española». La LOGSE, en su Disposición Adicional Segunda, estableció de manera unilateral que el régimen de estos profesores será de "contratación laboral, de duración determinada y coincidente con el curso escolar, a tiempo completo o parcialn. Se añade que la retribución de estos profesores será la que corresponda a los profesores interinos del mismo nivel educativo. Resulta llamativo que se establezca un régimen de contratación de estos profesores fuera de convenio, presumiendo que la Administración va a asumir dichos contratos, cuando lo más adecuado, en nuestra opinión, habría sido proponer la asignación de una cantidad global a favor de la Conferencia Episcopal, destinada al abono de los haberes de estos profesores, pero sin establecer una relación contractual directa entre la Administración y cada profesor de religión. Precisamente, eso es lo que ha hecho el Gobierno en la Orden de 9 de abril de 1999, que recoge el Convenio sobre Régimen Económico-Laboral de los profesores de Religión Católica. En resumen, la Administración educativa asume la condición de empleador y el profesor la de empleado, pero el contrato de carácter temporal, coincidente con el año académico, queda supeditado a la designación que corresponde a la autoridad eclesiástica.

Aparte de la lesión de los derechos laborales de estos profesores, que nunca podrán gozar de un contrato por tiempo indefinido, se produce una confusión de las funciones eclesiásticas y de las funciones estatales al vincular y supeditar la decisión de renovar o no el contrato a la libre designación por parte de la autoridad eclesiástica. Así lo que de acuerdo con la moral católica puede ser rechazable (contraer matrimonio con un divorciado) es plenamente legal de acuerdo con el ordenamiento jurídico español; sin embargo, la Administración educativa se ve obligada a no renovar un contrato por este motivo, si así lo dispone la autoridad eclesiástica. Es evidente que esta solución constituye una fuente de conflictos jurídicos, con una evidente lesión de derechos fundamentales, de la que son testigos los tribunales de justicia $y$, en estos momentos, el propio Tribunal Constitucional, que deberá resolver una cuestión de inconstitucionalidad elevada por un tribunal de justicia. 
c) Sin salirnos del ámbito educativo, habría que llamar la atención sobre el reconocimiento por la legislación universitaria vigente de tres regímenes jurídicos distintos: universidades públicas, universidades privadas y universidades de la Iglesia Católica. Lo que nació como un privilegio en el régimen de Franco, en el marco de un sistema de monopolio estatal de la Universidad, al reconocer a la Iglesia Católica y solo a ella el derecho a crear universidades, se ha consolidado como derechos adquiridos en los Acuerdos de 1979 y se ha extendido a las de nueva creación por una singular interpretación del Acuerdo por parte del Consejo de Estado (J. R. POLO), que ha hecho suya la LOU. El Acuerdo sobre Educación y Asuntos Culturales prevé que los centros universitarios que se establezcan por la Iglesia Católica "se acomodarán a la legislación que se promulgue con carácter general» (art. $X, 1)$. Aunque la redacción del texto no brilla precisamente por su precisión técnico-jurídico, parece claro que el acuerdo adoptado en el texto consiste en que las Universidades de la Iglesia, nacidas después de la firma de los Acuerdos, se han de someter plenamente a la legislación común vigente en la materia. Ello queda corroborado por la derogación de los artículos del Concordato, que servían de fundamento al Convenio de 1962, y a la exigencia de que las Universidades ya existentes habrán de acomodarse al la legislación vigente, salvo los derechos adquiridos al amparo de la norma de creación de las mismas. La interpretación que ha hecho el Consejo de Estado, sin embargo, ha sido que la sujeción a la legislación general del Estado se refiere únicamente a las actividades de la Universidad de la Iglesia y no a su reconocimiento.

En consecuencia, mientras las universidades públicas y las universidades privadas deber ser creadas o reconocidas por una ley de las Cortes Generales o de las Comunidades Autónomas, las Universidades de la Iglesia no necesitan este requisito, siendo suficiente, a estos efectos, el acto de creación por parte de la autoridad eclesiástica. A pesar de que el Acuerdo reitera, en varias ocasiones, la sujeción de las Universidades de la Iglesia al ordenamiento jurídico general e, incluso, insta a las ya existentes con anterioridad al Acuerdo de 1979 a que opten upor su adaptación a la legislación general sobre universidades no estatales", renunciando así a los derechos adquiridos, el resultado final ha sido que las universidades de la Iglesia - las anteriores y las posteriores a los Acuerdos de 1979- constituyen un grupo aparte, con un régimen jurídico diferenciado, que no puede esconder un trato de privilegio, al que, según parece, no están dispuestas a renunciar, a pesar de las declaraciones conciliares antes citadas. 
No podemos continuar con la exposición de otros ejemplos de exención del régimen general y acogimiento a un régimen especial con manifiestas connotaciones de régimen privilegiado por razones evidentes de espacio y tiempo. En una reciente tesis doctoral (P.C.PARDO) se han citado más de doscientas excepciones al régimen general que dan una idea del actual estado de la cuestión. Pero, como se nos ha pedido una reflexión sobre esta materia, no parece aventurado afirmar que la pretensión de nuestra Carta Magna de situar la cuestión religiosa en el ámbito de la persona, como expresión de la libertad ideológica y religiosa, tanto en el ámbito individual como colectivo, y con un régimen general y común para todos los individuos y comunidades, ha sido subvertido al recuperar la vía institucionalista, a través de inclusión en el texto constitucional de las llamadas relaciones de cooperación con la Iglesia, interpretadas posteriormente en clave concordataria.

La vía de los Acuerdos, ampliada a otras confesiones, sin ninguna tradición en el uso de este instrumento normativo, ha sido un vehiculo para establecer un trato diferencial y, en muchos casos, manifiestamente discriminatorio entre los individuos, por razón de sus creencias religiosas, y entre las diferentes confesiones. Los derechos y libertades inherentes a la dignidad de la persona humana, como proclama el artículo 10 de nuestra Constitución, deberían conducir a una régimen general y común de todos los individuos y de todas las comunidades ideológicas y religiosas, limitando las excepciones a este régimen en virtud de circunstancias excepcionales y plenamente justificadas. Al optar por un régimen pactado, siguiendo la vieja fórmula institucionalista, se ha puesto en entredicho el principio de igualdad y no discriminación.

La conclusión final no puede ser otra que, tras la experiencia de veinticinco años, se deberia proceder a la revisión de los Acuerdos con la Iglesia Católica y con las demás confesiones. El establecimiento de nuevos acuerdos, en caso de realizarse, debería tener lugar después de ampliar la legislación general a todas los individuos y comunidades, limitando los supuestos excepcionales, que se pudieran prever en los acuerdos, a supuestos también excepcionales y plenamente justificados. El éxito de la fórmula constitucional, al extender a todos los individuos y comunidades el derecho de libertad ideológica y religiosa, superando la tradicional confesionalidad estatal y el ocasional laicismo de la Segunda República, no debería verse empañado por situaciones de privilegio, originadas por la praxis institucionalista, que puedan poner en cuestión la igualdad y la no discriminación por razones ideológicas o religiosas. 